\title{
Novel Resection System for Direct Endoscopic Necrosectomy of Walled-Off Pancreas Necrosis: Have We Conquered the Final Frontier?
}

\author{
Surinder Singh Rana ${ }^{1}$ Rajesh Gupta ${ }^{2}$ \\ ${ }^{1}$ Department of Gastroenterology, Postgraduate Institute of Medical \\ Education and Research (PGIMER), Chandigarh, India \\ 2 Department of Surgical Gastroenterology, Postgraduate Institute of \\ Medical Education and Research (PGIMER), Chandigarh, India
}

\begin{abstract}
Address for correspondence Surinder Singh Rana, MD, DM, FASGE, Department of Gastroenterology, Postgraduate Institute of Medical Education and Research (PGIMER), Chandigarh 160012, India (e-mail: drsurinderrana@gmail.com).
\end{abstract}

J Digest Endosc 2021;12:258-260.

\begin{abstract}
Keywords

- endosonography

- necrosectomy

- pancreatitis

- stent

Surgical necrosectomy has been the traditional management for pancreatic necrosis and is done using blunt dissection. However, lack of dedicated endoscopic accessories has been a major limitation in direct endoscopic necrosectomy (DEN). Standard endoscopic accessories cannot effectively remove large necrotic material. Also, diameter of instrument channel of the endoscope limits the ability to use largediameter graspers that can remove large chunks of necrotic material. In this news, we discuss a recent study that has evaluated a new powered endoscopic debridement system for DEN.
\end{abstract}

Pancreatic fluid collections (PFCs) are important local complications of acute pancreatitis and are responsible for significant morbidity and mortality. ${ }^{1}$ The PFCs developing after an attack of acute necrotizing pancreatitis (ANP) have been classified as acute necrotic collections and walled-off necrosis (WON) depending on whether the collection has been enclosed by a well-formed wall or not. ${ }^{2}$ Pancreatic endotherapy has revolutionized the management of PFCs by providing a minimally invasive, effective, and safer interventional management option. Furthermore, the advent of endoscopic ultrasound (EUS) has expanded the management options for PFCs, with endoscopic treatment of nonbulging as well as distant PFCs being possible. ${ }^{3}$

Postprocedure fever due to infection of PFCs consequent to undrained solid necrotic debris via narrow-caliber plastic stents was a major limitation of endoscopic transmural drainage. ${ }^{4}$ The advent of large-diameter lumen-apposing metal stent (LAMS) has revolutionized the endoscopic man- agement of pancreatic necrotic collections by providing large drainage diameter $(15-20 \mathrm{~mm})$ that results in spontaneous drainage of thick necrotic collections in majority of patients. ${ }^{5}$ This has prompted endoscopists to drain PFCs with large amount of solid necrotic debris as well as necrotic collections in the early phase of illness when the wall is not well formed as well as the amount of solid necrotic debris is significant. ${ }^{6-9}$ Large amount of necrotic material cannot spontaneously drain through even large-caliber LAMS and it requires direct endoscopic necrosectomy (DEN) for its removal. DEN is a labor-intensive procedure and is associated with increased risk of complications, especially bleeding. ${ }^{10}$ Lack of dedicated accessories for DEN is also a major limitation.

Surgical necrosectomy has been the traditional management for pancreatic necrosis and is done using blunt finger dissection or ring forceps/sponge-holding forceps or gallstone-holding forceps to avoid bleeding. However, lack of dedicated endoscopic accessories has been a major
DOI https://doi.org/ 10.1055/s-0041-1741066. ISSN 0976-5042. (c) 2022. Society of Gastrointestinal Endoscopy of India. All rights reserved.

This is an open access article published by Thieme under the terms of the Creative Commons Attribution-NonDerivative-NonCommercial-License, permitting copying and reproduction so long as the original work is given appropriate credit. Contents may not be used for commercial purposes, or adapted, remixed, transformed or built upon. (https://creativecommons.org/ licenses/by-nc-nd/4.0/)

Thieme Medical and Scientific Publishers Pvt. Ltd., A-12, 2nd Floor, Sector 2, Noida-201301 UP, India 
limitation in DEN. Standard endoscopic accessories cannot effectively remove large necrotic material. Also, diameter of instrument channel of the endoscope limits the ability to use large-diameter graspers that can remove large chunks of necrotic material. Hence, effective solution for DEN can be a device or a chemical that can fragment the necrotic material into smaller pieces or liquify it so that it can be easily removed. The study by Stassen et al evaluated a new powered endoscopic debridement (PED) system for DEN. ${ }^{11}$ The authors in this elegant study have demonstrated that PED system is a safe and effective tool for DEN. It is creditable that the authors did not encounter device-related bleeding, a dreaded complication of necrosectomy. ${ }^{1}$ The PED device, described in the current study, is a mechanical device for necrosectomy and removes necrotic material by simultaneous cutting and suction using negative pressure.

The authors conducted a prospective, single-arm, multicenter trial at 10 sites ( 7 in the United State and 3 in Europe) in 30 patients with symptomatic WON (mean age: 55; 60\% male; $83 \%$ patients had pain and $16 \%$ had sepsis, with none having organ failure). The etiology of ANP was biliary in 18 (60\%) patients, alcohol in 5 (17\%), and unknown in 7 (23\%) patients. The mean length, width, and height of WON was $6.5 \pm 3.2 \mathrm{~cm}, 7 \pm 3.5 \mathrm{~cm}$, and $11.1 \pm 3.8 \mathrm{~cm}$, respectively, and the median necrotic debris content was $75 \%$ (interquartile range [IQR]: 40; mean: 70). All 30 patients underwent EUSguided drainage with placement of LAMS in 23 (76\%) patients, plastic stent in $5(17 \%)$ patients, and self-expanding metal stent in 2 (7\%) patients. An additional nasocystic drain was placed in 2 (7\%) patients, with the median time from placement of stent to index DEN being 7 days (IQR: 9).

These patients underwent DEN using a new PED system designed to simultaneously resect and remove solid debris within WON. The EndoRotor PED System (Interscope, Inc, Northbridge, Massachusetts, United States) with its innovative XT Catheter combine dissection, high-performance suction, and irrigation in a single, dedicated endoscopic instrument. The XT Catheter and high-flow suction combine dissection and suction of necrotic material and reduce risks associated with standard endoscopic accessories. The suction results in extraction of fragmented necrotic material and thus eliminates the need for instrument exchange. It has a 360-degree rotatable distal aperture that provides adequate access in challenging anatomy such as paracolic gutters. The XT Catheter is compatible with therapeutic endoscopes with at least a 3.2-mm working channel and the cutter speed can be set to high (1,700 RPM) or low $(1,000$ RPM) speed. The suction vacuum can be set between 50 and $550 \mathrm{~mm} \mathrm{Hg}$ of negative pressure.

The authors had several study end points, with the primary end point being safety of the EndoRotor PED System, defined as freedom from major device-related adverse events (AEs), and secondary end points being clearance of necrosis (at least $70 \%$ of the necrotic debris being removed as assessed by contrast-enhanced computed tomography [CECT] scan at day 21), total procedure time (scope-in to scope-out and start to end of debridement), adequacy of debridement after each procedure assessed endoscopically, total number of DEN procedures required to achieve clearance, length of hospital stay, and patient quality of life as assessed by 36-Item Short Form Survey (SF-36).

\section{Endoscopic Procedure}

DEN was performed using either monitored anesthesia care or general anesthesia with endotracheal intubation. The endoscope was advanced through the cystogastrostomy into the WON cavity and thereafter the XT Catheter was introduced into the WON cavity via the working channel of the endoscope and DEN was performed under direct endoscopic visualization. The necrosectomy catheter was controlled by endoscopist using the foot pedals. DEN was performed until patient showed clinical improvement and at least $70 \%$ of necrotic debris was removed with at least 2 days between consecutive procedures.

Sixty-four DENs were performed and the median number of procedures per patient was 1.5 and the median number of days between consecutive procedures was 6 days. In total, $67 \%$ of patients required only one or two procedures for resolution, whereas $13 \%$ of patients required three procedures and $7 \%$ of patients required four procedures for resolution. One patient underwent two procedures, with only $10 \%$ reduction of necrosis, and was considered as failure. This failed patient underwent DEN using conventional instruments and was not excluded from the analysis. The mean total procedure time was 117 minutes, with the mean EndoRotor time being 71 minutes. The median duration of hospitalization was 10 days (IQR: 22). At 21 days post DEN, cross-sectional imaging confirmed at least $70 \%$ removal of the necrotic debris in 29 out of 30 (97\%) patients.

A total of 9 serious AEs and 11 nonserious AEs occurred in 10 (33\%) patients and finally 3 were adjudicated by the safety board as possibly related to DEN procedure: gastrointestinal bleeding $(n=2)$ and pneumoperitoneum $(n=1)$. In total, 72 catheters were used for 64 procedures and 7 catheters broke due to the catheters being overextended. One catheter was clogged due to thick and sticky debris and was unable to resect necrotic debris. Regarding the quality of life, a significant improvement was found in four domains following DEN: physical functioning ( 36 vs. $58, p=0.002$ ), emotional wellbeing (61 vs. 68, $p=0.024$ ), energy/fatigue (28 vs. 37 , $p=0.040$ ), and pain (32 vs. 55, $p=0.001$ ). The authors concluded that patients undergoing DEN with EndoRotor system require fewer sessions of DEN when compared with studies using conventional instruments, and thus it appears to be safe and effective modality for DEN.

\section{Commentary}

Safe and effective DEN is a dream long cherished by interventional endoscopists, and various mechanical as well as chemical strategies have been employed for DEN with varying results. Endogenous gastric acid and bile have been reported as useful agents for chemical debridement of pancreatic necrosis and thus hasten recovery after DEN. ${ }^{12} \mathrm{Hy}-$ drogen peroxide and streptokinase have been also reported 


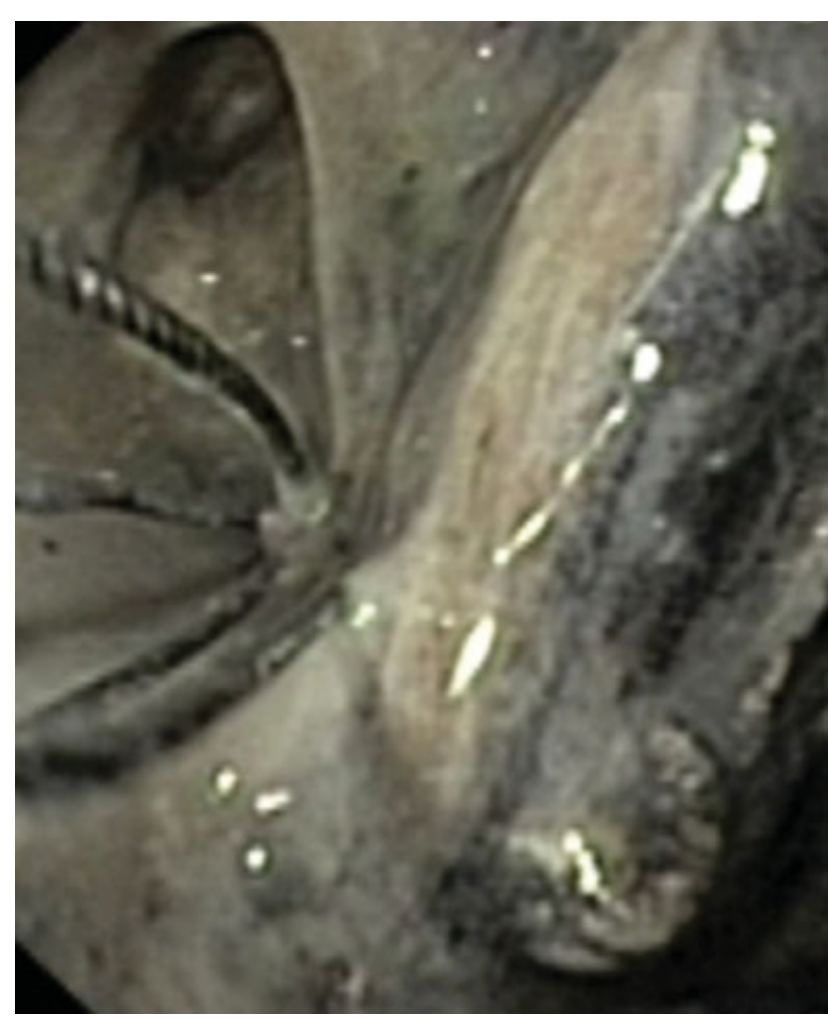

Fig. 1 Black pancreatic necrotic tissue being removed with the Dormia basket.

as chemical debriding agents for pancreatic necrosis with varying results. ${ }^{13,14}$ These various chemical debriding agents have improved the results of DEN, but the beneficial effects seem to be marginal and an effective chemical or mechanical device that effectively removes the necrotic material is the need of the hour. The new PED system that has been designed to simultaneously resect and remove solid debris within WON seems to be a step in the right direction. The authors have demonstrated that PED system is a safe and effective tool for DEN with no incidence of device-related bleeding, a dreaded complication of necrosectomy. Although the results of this study are encouraging, small sample size and lack of comparator arm are important limitations. It will be also interesting to study safety of this device in removing necrotic material near major mesenteric and splenic vessels as well as in patients with splenic vein thrombosis, a frequent occurrence in necrotizing pancreatitis. ${ }^{15}$ The effectiveness of this device for removing black or gray pancreatic tissue necrosis ( - Fig. 1), a real challenge in DEN, also needs to be studied in comparative trials. Endoscopic accessory that can effectively remove the necrotic debris without injuring blood vessels is a dream accessory for DEN and it seems that with this device the final frontier of safe and effective DEN is conquered!

Author Contributions

Both the authors drafted the manuscript.
Funding

None.

Conflict of Interest

None declared.

\section{References}

1 Rana SS. An overview of walled-off pancreatic necrosis for clinicians. Expert Rev Gastroenterol Hepatol 2019;13(04): 331-343

2 Banks PA, Bollen TL, Dervenis C, et al; Acute Pancreatitis Classification Working Group. Classification of acute pancreatitis-2012: revision of the Atlanta classification and definitions by international consensus. Gut 2013;62(01):102-111

3 Rana SS, Bhasin DK. Nonfluoroscopic endoscopic ultrasoundguided transmural drainage of pseudocysts: a pictorial technical review. Endosc Ultrasound 2015;4(02):92-97

4 Sharma V, Rana SS, Bhasin DK. Endoscopic ultrasound guided interventional procedures. World J Gastrointest Endosc 2015;7 (06):628-642

5 Guo J, Saftoiu A, Vilmann P, et al. A multi-institutional consensus on how to perform endoscopic ultrasound-guided peri-pancreatic fluid collection drainage and endoscopic necrosectomy. Endosc Ultrasound 2017;6(05):285-291

6 Rana SS, Gupta R. Endoscopic transluminal drainage in the early phase of acute necrotising pancreatitis. Am J Gastroenterol 2019; 114(04):688-689

7 Rana SS, Bhasin DK, Sharma RK, Kathiresan J, Gupta R. Do the morphological features of walled off pancreatic necrosis on endoscopic ultrasound determine the outcome of endoscopic transmural drainage? Endosc Ultrasound 2014;3(02):118-122

8 Rana SS, Verma S, Kang M, Gorsi U, Sharma R, Gupta R. Comparison of endoscopic versus percutaneous drainage of symptomatic pancreatic necrosis in the early $(<4$ weeks) phase of illness. Endosc Ultrasound 2020;9(06):402-409

9 Rana SS, Sharma R, Kishore K, Dhalaria L, Gupta R. Safety and efficacy of early ( $<4$ weeks of illness) endoscopic transmural drainage of post-acute pancreatic necrosis predominantly located in the body of the pancreas. J Gastrointest Surg 2021;25(09): 2328-2335

10 Rana SS, Shah J, Kang M, Gupta R. Complications of endoscopic ultrasound-guided transmural drainage of pancreatic fluid collections and their management. Ann Gastroenterol 2019;32(05): 441-450

11 Stassen PMC, de Jonge PJF, Bruno MJ, et al. Safety and efficacy of a novel resection system for direct endoscopic necrosectomy of walled-off pancreas necrosis: a prospective, international, multicenter trial. Gastrointest Endosc 2021:S0016-5107(21)01656-4

12 Rana SS, Sharma R, Gupta R. Can endogenous gastric acid and bile facilitate chemical debridement of walled off necrosis? Pancreatology 2019;19(02):398-399

13 Siddiqui AA, Easler J, Strongin A, et al. Hydrogen peroxide-assisted endoscopic necrosectomy for walled-off pancreatic necrosis: a dual center pilot experience. Dig Dis Sci 2014;59(03):687-690

14 Bhargava MV, Rana SS, Gorsi U, Kang M, Gupta R. Assessing the efficacy and outcomes following irrigation with streptokinase versus hydrogen peroxide in necrotizing pancreatitis: a randomized pilot study. Dig Dis Sci 2021 (e-pub ahead of print). Doi: 10.1007/s10620-021-07201-0

15 Rana SS, Sharma R, Ahmed SU, Gupta R. Endoscopic ultrasoundguided transmural drainage of walled-off pancreatic necrosis in patients with portal hypertension and intra-abdominal collaterals. Indian J Gastroenterol 2017;36(05):400-404 